\title{
Effects of type of physical exercise and leisure activities on the depression scores of obese Brazilian adolescent girls
}

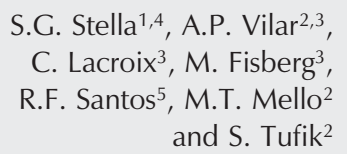

Correspondence

S.G. Stella

R. Marselhesa, 535

Vila Clementino

04020-060 São Paulo, SP

Brasil

E-mail: sgstella@psicobio.epm.br

Research supported by

Associação Fundo de Incentivo à

Psicofarmacologia.

Publication supported by FAPESP.

Received July 29, 2004

Accepted July 6, 2005

\author{
1Programa de Pós-Graduação em Nutrição, ${ }^{2}$ Departamento de Psicobiologia, \\ ${ }^{3}$ Departamento de Pediatria, Escola Paulista de Medicina, \\ Universidade Federal de São Paulo, São Paulo, SP, Brasil \\ ${ }^{4}$ Faculdade de Educação Física de Santo André, Faculdades Integradas, \\ Santo André, SP, Brasil \\ ${ }^{5}$ Associação Fundo de Incentivo à Psicofarmacologia, Instituto do Sono, \\ São Paulo, SP, Brasil
}

\begin{abstract}
Several studies have indicated that depressive states may lead to hypokinesia with diminished metabolic rate and energy use. Hypokinesia associated with certain eating behaviors may lead to an unfavorable energy balance that can contribute to the emergence and prevalence of obesity among children and adults. The purpose of the present study was to examine the possibility of reducing depression inventory scores in female adolescents with third-degree obesity while testing the effectiveness of different exercise programs in reducing anxiety and depression scores. The sample consisted of 40 female subjects (mean age $16 \pm 1.56$ years) divided into 4 groups (aerobic training, anaerobic training, leisure activities, and control). Subjects had a body mass index of $95 \%$ or more in relation to the 50th percentile. The aerobic program consisted of three ergometric bicycle sessions per week over a 3-month period (12 weeks) and the activities were prescribed after determining the anaerobic ventilatory threshold $\left(\mathrm{VO}_{2}\right.$ threshold). Anaerobic training was based on the Wingate anaerobic power test. The leisure program consisted of a varied range of activities (games, exercises, etc.). A nutritionist interviewed the members of these two groups and the control group every week in order to adapt them to the nutritional guidelines proposed for the study. The study showed that all three programs (aerobic exercise, anaerobic exercise and leisure activities) were effective in reducing body mass. However, we found a significant reduction when analyzing the depression scores only for aerobic exercise $(18.9 \pm 9.33$ to $10.6 \pm 9.56$ or $43.9 \%)$ but no significant alterations for anaerobic exercise $(11.36 \pm 5.23$ to $9.63 \pm$ 4.78 or $15.22 \%)$ and leisure (17.28 \pm 7.55 to $15.07 \pm 7.54$ or $12.78 \%)$, thus indicating that in principle this type of activity could be included to improve emotional well-being of obese adolescent girls.
\end{abstract}

Key words

- Adolescents

- Physical exercise

- Leisure activity

- Obesity 


\section{Introduction}

Depression is related to obesity in female adolescents but the same does not apply to male adolescents $(1,2)$. In addition to genetic and constitutional predispositions, there are other factors that have been indicated to be causes of depression symptoms in adolescents. These include new experiences, stressful events and high levels of fear (3-5).

Studies have pointed out that a state of depression may lead to hypokinesia, thus lowering metabolic rate and energy use $(6,7)$. Hypokinesia associated with certain eating behaviors and habits may induce an unfavorable energy balance contributing to the emergence and prevalence of obesity in children and adults (6).

Strauss and Pollack (8) have reported that obesity is the most frequent health problem faced by children and adolescents. Although there is a well-known correlation between obesity, low self-esteem and depression, social isolation is also common among overweight children and adolescents, although detailed descriptions are lacking.

Several studies have shown that physical activity or exercise may improve self-esteem and quality of life in the population in general $(9,10)$. Release of $B$-endorphin and dopamine during physical exercise produces a tranquilizing and analgesic effect. Regular exercise often leads to a relaxing post-effort effect and in general maintains a more stable state of psychosocial equilibrium in light of threats from the external environment (11).

The purpose of the present study was to examine the possibility of reducing anxiety and depression inventory scores in female adolescents with third-degree obesity using different exercise programs.

\section{Material and Methods}

\section{Methodology}

The sample comprised 40 female adoles- cents aged $14-19$ years $(16 \pm 1.56)$ divided into 4 groups: aerobic exercise, anaerobic exercise, leisure activities, and control. The selected volunteers had a body mass index (BMI) of $95 \%$ or more in relation to the 50th percentile (12). The subjects included in the study did not present contraindications for physical exercise.

The study was conducted in accordance with the guidelines of the Declaration of Helsinki and was formally approved by the Ethics Committee of the Federal University of São Paulo - Paulista Medical School (No. 047/01). All patients and their families received information about the protocol. The patients and their parents gave informed written consent.

Evaluations were conducted over a period of 4 days (1st day: clinical evaluation; 2nd day: anthropometrics and bone density measurement; 3rd day: ergospirometric testing for aerobic variables; 4 th day: the Wingate test $48 \mathrm{~h}$ after the $3 \mathrm{rd}$ day of evaluation).

\section{Evaluations}

Absorptiometric technique. The technique was used to evaluate body composition by dual X-ray absorptiometry (DEXA) (13).

Ergospirometric test. To evaluate aerobic capacity, the following variables were determined: maximum oxygen consumption $\left(\mathrm{VO}_{2 \text { peak }}\right)$, anaerobic ventilatory threshold $\left(\mathrm{VO}_{2 \text { threshold }}\right)$, maximum heart rate $\left(\mathrm{HR}_{\text {peak }}\right)$, and anaerobic ventilatory threshold rate.

Wingate test. To evaluate anaerobic variables, the following parameters were determined: maximum or peak power test $\left(\mathrm{PT}_{\text {peak }}\right.$, watts $/ \mathrm{kg}$ ), average power ( $\mathrm{PT}_{\text {average, }}$ watts/ $\mathrm{kg})$, and fatigue index (\%).

Beck Depression Inventory. There are 21 clinical symptoms of depression. Eleven of the 21 items refer to cognitive symptoms of depression, while the remaing 10 items cover affective, behavioral, somatic, and interpersonal aspects of depression. Each item consists of a series of four-statement scale to 
indicate increasing depressive symptomatology. The scores 5-9 indicate that these ups and downs are considered normal; 10-18, mild to moderate depression; $19-29$, moderate to severe depression, and 30-63, severe depression. The scale was applied on the first day of evaluation and after the training period (14).

Trait-State Anxiety Inventory. The scales were applied on the first day of evaluation and at the end of the training period. Each part contains 20 statements. Responses are on a scale from 1 to 4 . Anxiety state refers to how individuals feel "at the moment" and anxiety trait to how they "generally feel". Each part varies from 20 to 80 points, and the scores indicate low (0-30), medium (3149 ) or high (50 or more) levels of anxiety (15).

\section{Training}

The physical fitness program comprised three ergonometric bicycle sessions per week over a 3-month period (12 weeks).

Aerobic training. Aerobic activities were prescribed by determining the anaerobic ventilatory threshold $\left(\mathrm{VO}_{2 \text { threshold }}\right)$ according to the American College of Sports Medicine (16). Volunteers exercised for 40-min sessions during the first month. In the second month of activities, the sessions were extended to $50 \mathrm{~min}$ and in the third month to 60 min. The higher training overload was applied to the duration rather than to the intensity of the activity.

Anaerobic training. The anaerobic training prescription was based on data obtained in the initial evaluation (Wingate anaerobic power test) (17), using "interval training" methods (18-20), at a frequency of three times a week, for a duration of $40 \mathrm{~min}$ in the first month, 50 min in the second month, and $60 \mathrm{~min}$ in the third month. The interval work took the form of ergometric cycle series with a load equivalent to 25 watts $\mathrm{x} 0.8 \%$ of the volunteer's weight, for $30 \mathrm{~s}$, with an interval for active recovery (walking) of $3 \mathrm{~min}$ between series. In the first month, volunteers did 11 series on the ergometric bicycle at 80 RPM pedal speed. Training for the first month consisted of three 40-min sessions per week. In the second month, the work-out volume was increased to 14 series (anaerobic interval) per volunteer with a $10 \%$ increment over the initial load, with a total of $50 \mathrm{~min}$ of training time per day. During the third month, volunteers started to do 14 series of $45 \mathrm{~s}$ each, with the same load and the same recovery time as in the second month, with a total of 60 min of training per day.

\section{Leisure}

The adolescents practiced physical activities such as games and exercises, etc., in a weekly session lasting $60 \mathrm{~min}$ at a sports center. The aim of this activity was to encourage them to practice a new habit of physical activity not characterized as specific training.

\section{Control group}

This group was interviewed by the nutritionist every week for adaptation to the nutritional orientation proposed in the study and did not take part in leisure or training activities.

The Student $t$-test was used for the analysis of intra-group alterations of variables and two-way ANOVA was used to compare the effects of training in the different groups.

\section{Results}

The results are presented according to training and control groups, with physiological (Table 1) and psychological variables (Figure 1) reported as means $\pm \mathrm{SD}$ for the pre- and post-training periods.

The aerobic, anaerobic, and leisure groups showed a significant reduction in body mass (weight; $\mathrm{P}=0.02)$, BMI $(\mathrm{P}=0.02)$ and total 
body fat mass $(\mathrm{P}=0.04)$. The control group also had a significantly reduced fat mass index $(\mathrm{P} \leq 0.04)$. The anaerobic group showed a significant increase in total fat-free mass. There were no significant differences between groups regarding these variables (Table 1).

Analysis of the cardiorespiratory variables showed a significant increase in $\mathrm{VO}_{\text {2peak }}$, $\mathrm{P} \leq 0.006$, oxygen consumption at the $\mathrm{VO}_{2 \text { threshold }}, \mathrm{P} \leq 0.04$, and anaerobic ventilatory threshold load, $\mathrm{P} \leq 0.02$, in the aerobic, anaerobic and leisure groups, but not in the control group, whose variables showed no significant alterations (Table 1). Inter-group comparison showed no significant differences.

Pre- and post-treatment comparison of $\mathrm{HR}_{\text {peak }}$ showed a significant difference only for the leisure group $(\mathrm{P}=0.007)$ but not for any other group (Table 1). No significant differences in the other variables studied $\left(\mathrm{HR}_{\text {threshold }}, \mathrm{PT}_{\text {peak }}, \mathrm{PT}_{\text {average }}\right)$ were detected in any group (Table 1).

When analyzing the depression scores, we found a significant reduction only in the aerobic group $(18.9 \pm 9.33$ to $10.6 \pm 9.56$ or $43.9 \%, \mathrm{P}=0.01$ ) but no significant alterations in the anaerobic exercise (11.36 \pm 5.23 to $9.63 \pm 4.78$ or $15.22 \%$ ) and leisure $(17.28 \pm 7.55$ to $15.07 \pm 7.54$ or $12.78 \%$; Figure 1A). The Trait-State indices showed no significant variations between pre- and post-exercise levels for the aerobic, anaerobic and leisure groups $(\mathrm{P} \leq 0.51)$, and there was only a significant decrease in Trait Anxiety in the control group $(\mathrm{P}=0.01$; Figure 1B).

\section{Discussion}

The reduction in anxiety index found in the control group when comparing pre- and post-study scores may be partly explained on the basis of data reported by Strauss and Pollack (8). The fact that the subjects ob-

Table 1. Effect of type of physical activity on cardiovascular parameters, BMI and fat levels of obese adolescent girls.

\begin{tabular}{|c|c|c|c|c|c|c|c|c|c|c|c|c|}
\hline & \multicolumn{2}{|c|}{ Control group } & \multirow{2}{*}{$\begin{array}{c}\Delta \\
(\%)\end{array}$} & \multicolumn{2}{|c|}{ Leisure activity } & \multirow{2}{*}{$\begin{array}{c}\Delta \\
(\%)\end{array}$} & \multicolumn{2}{|c|}{ Aerobic group } & \multirow{2}{*}{$\begin{array}{c}\Delta \\
(\%)\end{array}$} & \multicolumn{2}{|c|}{ Anaerobic group } & \multirow{2}{*}{$\begin{array}{c}\Delta \\
(\%)\end{array}$} \\
\hline & Pre & Post & & Pre & Post & & Pre & Post & & Pre & Post & \\
\hline Body mass $(\mathrm{kg})$ & $88.36 \pm 9.03$ & $83.62 \pm 7.89^{\star}$ & -5.5 & $93.18 \pm 15.18$ & $89.23 \pm 15.26^{\star}$ & -4.3 & $94.4 \pm 10.9$ & $91.6 \pm 11.7^{\star}$ & -2.9 & $89.16 \pm 15.87$ & $86.27 \pm 15.85^{*}$ & -3.3 \\
\hline BMI $\left(\mathrm{kg} / \mathrm{m}^{2}\right)$ & $33.52 \pm 2.72$ & $31.66 \pm 1.98^{*}$ & -5.5 & $35.64 \pm 4.78$ & $34.12 \pm 4.8^{*}$ & -4.3 & $36.8 \pm 4.1$ & $35.7 \pm 4.4^{*}$ & -2.9 & $34.38 \pm 4.81$ & $33.25 \pm 4.73^{\star}$ & -3.3 \\
\hline \multicolumn{13}{|l|}{ Ergospirometric test } \\
\hline $\begin{array}{l}\mathrm{VO}_{2 \text { peak }} \\
\left(\mathrm{ml} \mathrm{kg}^{-1} \mathrm{~min}^{-1}\right)\end{array}$ & $25.71 \pm 2.69$ & $25.15 \pm 4.63$ & -2.2 & $23.02 \pm 4.74$ & $26.4 \pm 4.02^{\star}$ & 13 & $19.7 \pm 3.7$ & $25.0 \pm 3.6^{*}$ & 21.2 & $23.77 \pm 3.62$ & $26.90 \pm 3.35^{\star}$ & 11.7 \\
\hline $\mathrm{HR}_{\text {peak }}(\mathrm{bpm})$ & $174.5 \pm 3.74$ & $171.25 \pm 12.7$ & -2 & $171.46 \pm 10.42$ & $176.76 \pm 11.67^{\star}$ & 3 & $179.8 \pm 10.9$ & $182.0 \pm 9.7$ & 1.2 & $175.36 \pm 11.2$ & $179.63 \pm 11.52$ & 2.4 \\
\hline $\begin{array}{l}\mathrm{VO}_{\text {2threshold }} \\
\left(\mathrm{ml} \mathrm{kg}{ }^{-1} \mathrm{~min}^{-1}\right)\end{array}$ & $15.87 \pm 1.82$ & $15.07 \pm 3.06$ & -5 & $14.01 \pm 1.86$ & $15.73 \pm 2.52^{\star}$ & 10.9 & $12.7 \pm 1.7$ & $14.9 \pm 2.3^{*}$ & 14.7 & $13.79 \pm 2.76$ & $15.58 \pm 2.55^{\star}$ & 11.5 \\
\hline $\mathrm{HR}_{\text {threshold }}(\mathrm{bpm})$ & $134 \pm 11.27$ & $137.8 \pm 24.45$ & 2.7 & $132.33 \pm 9.85$ & $134.16 \pm 13.07$ & 1.3 & $146.7 \pm 17.1$ & $143.3 \pm 12.7$ & -2.3 & $131.72 \pm 14.22$ & $136 \pm 10.04$ & 3.2 \\
\hline Watts threshold & $75.0 \pm 0$ & $75.0 \pm 13.36$ & 0 & $67.30 \pm 15.76$ & $80.76 \pm 14.97^{\star}$ & 16.6 & $66.6 \pm 7$ & $83.0 \pm 33.0^{*}$ & 19.7 & $63.63 \pm 20.5$ & $81.8 \pm 11.6^{*}$ & 32 \\
\hline \multicolumn{13}{|l|}{ DEXA } \\
\hline Fat mass $(\mathrm{kg})$ & $35.49 \pm 5.54$ & $32.80 \pm 4.38^{\star}$ & -7.5 & $38.47 \pm 8.18$ & $35.13 \pm 7.73^{\star}$ & -8.6 & $41.0 \pm 8.1$ & $39.0 \pm 7.5^{\star}$ & -4.8 & $37.46 \pm 8.8$ & $35.16 \pm 9.1^{*}$ & -6.2 \\
\hline Fat free $(\mathrm{kg})$ & $47.13 \pm 3.49$ & $45.95 \pm 3.48$ & -2.6 & $48.32 \pm 6.2$ & $48.66 \pm 6.75$ & -0.6 & $47.5 \pm 3.1$ & $47.0 \pm 3.6$ & -1 & $46.07 \pm 5.51$ & $46.79 \pm 5.36^{\star}$ & 1.6 \\
\hline \multicolumn{13}{|l|}{ Wingate test } \\
\hline $\mathrm{PT}_{\text {peak }}$ (watts $/ \mathrm{kg}$ ) & $3.64 \pm 0.96$ & $4.16 \pm 1.28$ & 2.5 & $4.34 \pm 1.45$ & $4.86 \pm 1.79$ & 10.6 & $4.0 \pm 0.9$ & $4.7 \pm 1.5$ & 14.8 & $4.40 \pm 1.16$ & $4.86 \pm 1.10$ & 9.5 \\
\hline $\mathrm{PT}_{\text {average }}$ (watts $/ \mathrm{kg}$ ) & $2.39 \pm 1.10$ & $1.92 \pm 0.871$ & -19.6 & $1.79 \pm 1.56$ & $1.79 \pm 1.06$ & 0 & $1.9 \pm 0.9$ & $3.0 \pm 0.5$ & 36.6 & $2.35 \pm 0.87$ & $3.24 \pm 0.68$ & 27.4 \\
\hline
\end{tabular}

Ten subjects per group were studied. $\mathrm{BMI}=$ body mass index; $\mathrm{VO}_{2 \text { peak }}=$ maximal oxygen uptake; $\mathrm{HR}_{\text {peak }}=$ heart rate at maximal oxygen uptake; $\mathrm{VO}_{2 \text { threshold }}=$ ventilatory threshold; $\mathrm{HR}_{\text {threshold }}=$ heart rate at ventilatory threshold; $\mathrm{DEXA}=$ dual X-ray absorptiometry; fat mass = total fat mass; fat free = total fat-free mass; $\mathrm{PT}_{\text {peak }}=$ peak power; $\mathrm{PT}_{\text {average }}=$ average power. ${ }^{*} \mathrm{P}<0.05$ compared to pre-test (Student $t$-test). 
tained professional attention to follow the nutritional guidelines proposed in the study is in itself a factor that reduces social isolation and improves the scores for emotional states among overweight children and adolescents. Reduced body mass (kg), BMI and total fat mass may have been due to alterations in eating behavior as part of the nutritional instructions proposed by the professional, in agreement with the data reported by Strauss and Pollack (8) and Schlicker et al. (6). The fact that subjects continued to adhere to the eating habits proposed in the study may be partly explained by positive reinforcement since they were being given attention by the professional (reduced social isolation) and partly by the reduced BMI, since variations in the control group were higher $(6 \%)$ than in the other groups, which may also explain their lower anxiety scores.

Although we cannot determine precisely the factor that first had an influence, one of the most likely scenarios is a chain reaction in which the attention given by the professional may have led to improvement in anxiety indexes, which in turn led to a less unfavorable eating behavior (6) and consequently to a BMI reduction. This acted as feedback into the process, favoring its sustainability. This line of thought agrees with Eisenberg et al. (2), who reported the importance of BMI in adolescents as a deficit reducing factor in their emotional well-being.

There is a broad agreement among authors as to which type of exercise should be prescribed. Research conducted by Altchiler and Motta (21), Raglin and Wilson (22), Orwin (23), and Morgan (24) concluded that aerobic exercise is more effective than anaerobic exercise in the treatment of anxiety disorder. Regarding depressive disorder, some investigators argue that aerobic exercise is also the most effective (25-27) but there is also research showing that both aerobic and anaerobic exercise may be effective $(28,29)$.

The overall improvement in scores and indexes of $\mathrm{BMI}, \mathrm{VO}_{2 \text { peak }}, \mathrm{VO}_{2 \text { threshold }}, \mathrm{PT}_{\text {peak }}$, $\mathrm{PT}_{\text {average, total fat mass, and total fat-free }}$ mass for the aerobic training, anaerobic, and leisure groups may be explained by the activities proposed and dietary modifications suggested by the professional, in agreement with literature data $(6,7,30)$. This further highlights the importance of physical activity and exercise in preventing obesity and its repercussions on emotional states, such as depressive symptoms (6). The fact that our own study found improvements in aspects related to depression in the aerobic exercise group alone may be due to the greater effectiveness of this type of activity in improving mood states. The effectiveness of this type of activity may be related to the time for the organism to respond, which may be shorter for this activity than for others. Perhaps longer training periods for the other types of activity (anaerobic and leisure) would produce a similar effect, and this could be an issue for further research.

Note also that physical exercise may lead to a series of physiological and biochemical alterations involving release of neurotransmitters and activation of specific receptors that help reduce depression inventory scores,

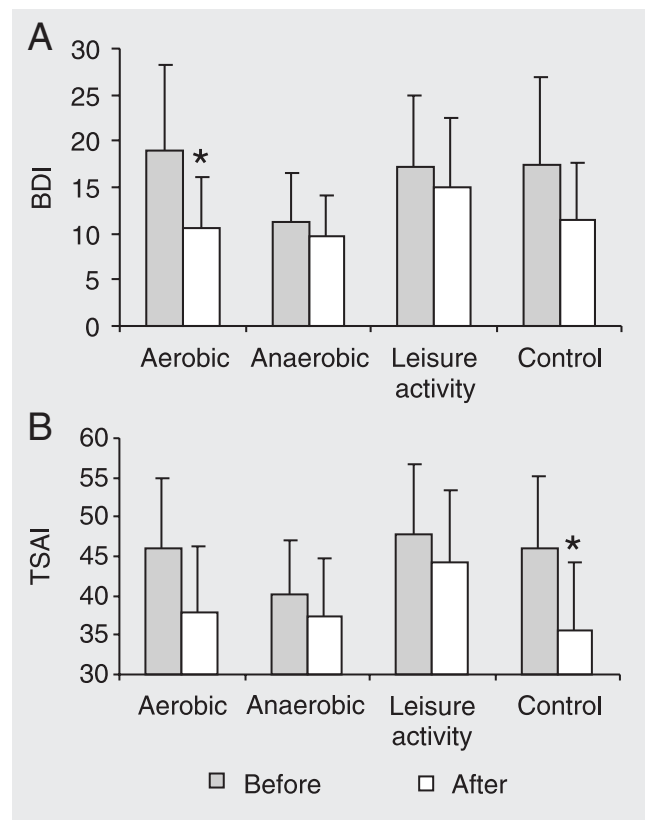

Figure 1. Effect of exercise on Beck Depression Inventory (BDI) (A) and Trait-State Anxiety Inventory (TSAI) (B) scores of obese adolescent girls. Within-group pre- and posttreatment data were compared by the Student $t$-test and between-group data were compared by one-way ANOVA for repeated measures for 10 subjects per group. ${ }^{*} \mathrm{P}<0.05 \mathrm{com}$ pared to pretreatment. 
since some of these neurotransmitters contribute to the emergence or reduction of these disorders (31). In agreement with this hypothesis, Struder and Weicker $(32,33)$ suggest a relationship between reduced body mass and lower fat percentages and lower plasma serotonin (5-HT) concentrations. These changes may be related to the biochemical alterations mentioned by Costil et al. (34), whereby higher plasma concentrations of free fatty acids are observed after prolonged exercise due to lipolysis. Free fatty acids dislocate albumin from tryptophan and thus boost the concentrations of the free tryptophan (Trp-f) portion responsible for the synthesis of 5-HT. Combined with these alterations, the main competitors of Trp- $\mathrm{f}$ in crossing the blood brain barrier, the plasma concentrations of branched chain amino acids (BCAAs) are reduced due to the increase in their capacity and oxidation by exercised muscles. This plasma reduction of BCAAs induces an increase in the proportion of Trpf/BCAA, and transport of Trp-f to the central levels becomes more probable, thus raising 5-HT concentrations and helping reduce depression inventory scores, since 5-HT levels are directly related to the incidence of depression.

Martinsen (28) reported that several experiments have been conducted on depressed subjects with exercise as an intervening factor. All of these studies reached the same conclusion: aerobic or even anaerobic exercise is as effective as any other therapy in the rehabilitation of depressed patients as long as the severity of depression is average to moderate.

The literature, therefore, is unanimous in concluding that physical activity may be useful in the treatment of depression, not as the only method but rather as an option in dealing with this psychological disorder. However, we did not find research using aerobic exercise in the treatment of depression as a special strategy for obese adolescent girls.

On the basis of the data obtained in the present study, we conclude that aerobic, anaerobic and leisure programs, or a restricted diet program, were effective in decreasing BMI in female adolescents with severe obesity. Regarding the depression inventory scores, only the aerobic group demonstrated a significant reduction, thus indicating that this type of activity may produce much faster improvement.

These data suggest that the regular practice of physical exercise guided by physiological parameters obtained from cardiorespiratory and ergospirometric evaluation, and with training intensity and volume corresponding to the anaerobic ventilatory threshold I could be included in programs aiming to improve the physical and emotional well-being of obese adolescents aged 14-19 years.

\section{Acknowledgments}

We are grateful to the anonymous reviewers for their help and suggestions about improving the manuscript.

\section{References}

1. Richardson LP, Davis R, Poulton R et al. (2003). A longitudinal evaluation of adolescent depression and adult obesity. Archives of Pediatrics and Adolescent Medicine, 157: 739-745.

2. Eisenberg ME, Neumark-Sztainer D \& Story M (2003). Associations of weight-based teasing and emotional well-being among adolescents. Archives of Pediatrics and Adolescent Medicine, 157: 733738.

3. Barnow S, Bernheim D, Schroder C et al. (2003). Obesity in child- hood and adolescence - first results of a multimodal intervention study in Mecklenburg-Vorpommern. Psychotherapie, Psychosomatik, Medizinische Psychologie, 53: 7-14.

4. Ackard DM, Neumark-Sztainer D, Story M et al. (2003). Overeating among adolescents: prevalence and associations with weight-related characteristics and psychological health. Pediatrics, 111: 6774.

5. Wingood GM, DiClemente RJ, Harrington K et al. (2002). Body 
image and African American females' sexual health. Journal of Women's Health and Gender-Based Medicine, 11: 433-439.

6. Schlicker SA, Borra ST \& Regan C (1994). The weight and fitness status of United States children. Nutrition Reviews, 52: 11-17.

7. Jefferson JW \& Greist JH (1999). Mood disorders. In: Hales RE, Yudofs SC \& Tallbot YA (Editors), Essentials of Clinical Psychiatry. American Psychiatric Press, Washington, DC, USA.

8. Strauss RS \& Pollack HA (2003). Social marginalization of overweight children. Archives of Pediatrics and Adolescent Medicine, 157: $746-752$.

9. Stephens T (1998). Physical activity and mental health in the United States and Canada: evidence from four population surveys. Preventive Medicine, 17: 35-47.

10. Paffenbarger Jr RS, Lee IM \& Leung R (1994). Physical activity and personal characteristics associated with depression and suicide in American college men. Acta Psychiatrica Scandinavica, 377 (Suppl): 16-22.

11. Lobstein DD \& Rasmussen CL (1991). Decreases in resting plasma beta endorphin and depression scores after endurance training. Journal of Sports Medicine and Physical Fitness, 31: 543-551.

12. Must A, Dallal GE \& Dietz WH (1991). Reference data for obesity: 85th and 95th percentiles of body mass index (wt/ht2) - a correlation. American Journal of Clinical Nutrition, 53: 839-846.

13. Mazess RB (1990). Dual-photon absorptiometry: depleted sources inappropriate in obese patients with narrow collimation. Journal of Nuclear Medicine, 31: 538-540.

14. Beck AT, Ward CH, Mendelson M et al. (1961). An inventory for measuring depression. Archives of General Psychiatry, 4: 53-63.

15. Gorenstein C \& Andrade L (1996). Validation of a Portuguese version of the Beck depression inventory and the state-trait anxiety inventory in Brazilian subjects. Brazilian Journal of Medical and Biological Research, 29: 453-457.

16. American College of Sports Medicine - ACSM Position Stand (1998). Exercise and physical activity for older adults. Medicine and Science in Sports and Exercise, 30: 992-1008.

17. Bar-Or O (1987). The Wingate Anaerobic Test. An update on methodology, reliability and validity. Sports Medicine, 4: 381-394.

18. Laursen PB, Shing CM, Peake JM et al. (2002). Interval training program optimization in highly trained endurance cyclists. Medicine and Science in Sports and Exercise, 34: 1801-1807.

19. Vandewalle H, Peres G, Heller J et al. (1985). All out anaerobic capacity tests on cycle ergometers. A comparative study on men and women. European Journal of Applied Physiology and Occupational Physiology, 54: 222-229.

20. Wilkinson JG, Martin DT, Adams AA et al. (2002). Iron status in cyclists during high-intensity interval training and recovery. International Journal of Sports Medicine, 23: 544-548.

21. Altchiler L \& Motta R (1994). Effects of aerobic and nonaerobic exercise on anxiety, absenteeism, and job satisfaction. Journal of Clinical Psychology, 50: 829-840.

22. Raglin JS \& Wilson M (1996). State anxiety following $20 \mathrm{~min}$ of bicycle ergometer exercise at selected intensities. International Journal of Sports Medicine, 17: 467-471.

23. Orwin A (1973). The running treatment: A preliminary communication of a new use for an old therapy (physical activity) in the agoraphobic syndrome. British Journal of Psychiatry, 122: 175-179.

24. Morgan WP (1973). Influence of acute physical activity on state anxiety. National College Physical Education Association for Men Proceedings, 3: 113-121.

25. Coyle CP \& Santiago MC (1995). Aerobic exercise training and depressive symptomatology in adults with physical disabilities. Archives of Physical Medicine and Rehabilitation, 76: 647-652.

26. Brown DK (1997). Childhood and adolescent weight management. In: Danton S (Editor), Overweight and Weight Management. Aspen Publishers, Inc., New York.

27. Greist JH, Klein MH, Eischens RR et al. (1979). Running through your mind. Journal of Psychosomatic Research, 22: 259-294.

28. Martinsen EW (1994). Physical activity and depression: clinical experience. Acta Psychiatrica Scandinavica, 377 (Suppl): 23-27.

29. May A (1995). Using exercise to tackle postnatal depression. Health Visitor, 68: 146-147.

30. Lowry R, Wechsler H, Galuska DA et al. (2002). Television viewing and its associations with overweight, sedentary lifestyle, and insufficient consumption of fruits and vegetables among US high school students: differences by race, ethnicity, and gender. Journal of School Health, 72: 413-421.

31. Meeusen R \& Demeirleir K (1995). Exercise and brain neurotransmission. Journal of Sports Medicine and Physical Fitness, 20: 160188.

32. Struder HK \& Weicker H (2001). Physiology and pathophysiology of the serotonergic system and its implications on mental and physical performance. Part I. International Journal of Sports Medicine, 22: 467-481.

33. Struder HK \& Weicker H (2001). Physiology and pathophysiology of the serotonergic system and its implications on mental and physical performance. Part II. International Journal of Sports Medicine, 22 : 482-497.

34. Costil DL, Bowers R \& Braunam G (1971). Muscle glycognen utilization during prolonged exercise on successive days. Journal of Applied Physiology, 31: 834-838. 